\title{
PHYLOGENETIC ASSESSMENT OF ARTHROCNEMUM MACROSTACHYUM (CHENOPODIACEAE) GENOTYPES, USING RAMP MARKERS
}

\author{
Basel SaleH
}

\begin{abstract}
Random amplified microsatellite polymorphism (RAMP) marker technique was employed to test its usefulness for assessing phylogenetic relationships in three genotypes of Arthrocnemum macrostachyum (Moric.) Moris. \& Delponte from Syria. PCR reactions with 21 RAMP primer combinations (PCs) distinguished 145 loci, 139 of which (95.862\%) were polymorphic. The $(\mathrm{AG})_{8} \mathrm{TC} / \mathrm{OPE} 18$ primer combination generated the highest number of fragments (11 amplicons), and the (AC) $)_{8} \mathrm{~T} / \mathrm{OPE} 04$ primer combination the fewest (4 amplicons). Average estimated polymorphic information content (PIC) was 0.431 , with an average marker index (MI) of 2.836. Analysis by the unweighted pair group method using arithmetic averages (UPGMA) was performed and a dendrogram was constructed. UPGMA cluster analysis based on RAMP markers distinguished genotype 2, suggested here to be a subspecies, from genotypes 1 and 3. In this study the RAMP marker method proved to be a reliable tool for discriminating and estimating genetic diversity within A. macrostachyum.
\end{abstract}

Key words: Arthrocnemum macrostachyum, genotype, polymorphism, RAMP marker

Basel Saleh, Department of Molecular Biology and Biotechnology, Atomic Energy Commission of Syria, P.O. Box 6091, Damascus, Syria; e-mail: ascientific@aec.org.sy

\section{INTRODUCTION}

Interest in halophytes is increasing, in view of their potential use for reclamation of salt-affected land. Arthrocnemum macrostachyum (Moric.) Moris. $\&$ Delponte is a halophytic stem-succulent shrub or subshrub inhabiting salt marshes of the Mediterranean region (Saleh 2011a; Vicente et al. 2007), distributed mainly in the Mediterranean and Saharo-Arabian regions and extending far into adjacent regions (Zohary 1966). Until 2011 there were no reports of its occurrence in Syria (Saleh $2011 \mathrm{a}, \mathrm{b})$. In that year this species was found in coastal regions of Syria, forming pure or mixed populations with other halophytic species such as Juncus acutus L., Inula chritmoides L. or Halimione portulacoides (L.) Aellen (Saleh 2011a).

Arthrocnemum macrostachyum belongs to subfamily Salicornioideae, family Chenopodiaceae. Salicornioideae comprises 14-16 genera, within which ca 90 species exist. Globally, 51 species of the genus Arthrocnemum are reported (Kung et al. 1979).
The genetics and phylogenetic relationships of A. macrostachyum are insufficiently known, and the position of Arthrocnemum is not adequately clarified at genetic level. Nor is the taxonomy of Salicornioideae clear cut. For example, the taxonomy of Australian representatives of the Salicornioideae is complicated by the presence of large subspecies complexes as well as putative hybrids (Wilson 1980). Polyploidy is also evident at both species and subspecies level (Shepherd \& Yan 2003).

In Syria the different ecosystems form an important center of origin and biodiversity for many plants (Zohary 1973). In the rich Syrian flora, Barkoudah et al. (2000) reported ca 3150 species belonging to 919 genera distributed in 133 families.

Different marker systems are used in genetic diversity studies. Random amplified polymorphic DNA (RAPD) analysis is one of the molecular techniques used for assessing genetic varia- 
tion in many crops and other plants (Williams et al. 1990; Saleh 2011a; Ding et al. 2013; Manners et al. 2013; Mondal et al. 2008; Noormohammadi et al. 2013). Inter-simple sequence repeat (ISSR) markers have also been extensively applied in fingerprinting studies for plant breeding programs (Mondal et al. 2008; Saleh 2011a; Ding et al. 2013; Manners et al. 2013; Noormohammadi et al. 2013).

The random amplified microsatellite polymorphism (RAMP) system is based on a set of PCRbased markers that have been successfully used in genetic studies of various plant crops such as peach cultivars (Cheng et al. 2001), Leymus species (Yang et al. 2006), tobacco (Liu et al. 2009), Tunisian Phoenix dactylifera L. (Soumaya et al. 2011), Secale cereale L. (Smolik 2012) and tetraploid Gossypium hirsutum L. (Noormohammadi et al. 2012).

Most studies of Arthrocnemum macrostachyum have focused on morphology, and little work has been done on its genetic diversity. The present study was designed to assess the value of RAMP as a marker system for assessing the phylogenetic relationships of this species.

\section{MATERIAL AND METHODS}

Three genotypes of A. macrostachyum species occurred at the same location on the western coast of Syria, $12 \mathrm{~km}$ north of Latakia. These genotypes formed the source of samples for DNA isolation, collected in the spring season. Total genomic DNA was isolated from young leaves of the three genotypes (bulk of 5 plants/ genotype) by the CTAB (cetyltrimethylammonium bromide) protocol as described by Doyle and Doyle (1987), with minor modifications. The DNA concentration was quantified by DNA fluorimetry and it was kept at $-80^{\circ} \mathrm{C}$ until use.

The RAMP technique uses combinations of two DNA-based PCR markers (RAPD and ISSR primers). PCR amplification was performed as previously described by Saleh (2011b). A RAMP system of 21 primer combinations (PCs: RAPD/ISSR) was applied for fingerprinting.

The amplification reaction was performed in a $25 \mu 1$ reaction volume containing $1 \mathrm{X}$ PCR buffer, $2 \mathrm{mM}$ $\mathrm{MgCl}_{2}, 0.25 \mathrm{mM}$ dNTPs, 25 pmol primer (Operon Technologies, USA), 1.5 U Taq DNA polymerase (Fer- mentas) and 30 ng template DNA. PCR amplification was carried out in a T-gradient thermal cycler (Bio-Rad, Hercules, USA). It was programmed for 35 cycles after initial denaturation for $4 \mathrm{~min}$ at $94^{\circ} \mathrm{C}$. Each cycle consisted of $1 \mathrm{~min}$ denaturation at $94^{\circ} \mathrm{C}, 2$ min annealing at $38^{\circ} \mathrm{C}$ and $2 \mathrm{~min}$ extension at $72^{\circ} \mathrm{C}$, followed by $7 \mathrm{~min}$ final extension at $72^{\circ} \mathrm{C}$. The PCR products were then separated on $1.5 \%$ ethidium bromide-stained agarose (Bio-Rad) in $0.5 \mathrm{X}$ TBE buffer. PCR products were separated by electrophoresis at $85 \mathrm{~V}$ for $2.5 \mathrm{~h}$, and then visualized with a UV transilluminator. The molecular weight of PCR amplification products was estimated with a $1 \mathrm{~kb}$ DNA ladder standard.

The products amplified by RAMP technique were screened and photographed under UV. The presence or absence of each size class was scored as 1 or 0 . The estimated percent disagreement values (PDVs) were used to generate a matrix by the unweighted pair group method using arithmetic averages (UPGMA) in Statistica. Then this matrix was used to calculate Jaccard genetic distance. Polymorphic information content (PIC) values were calculated for each RAMP PC according to the formula

$$
\mathrm{PIC}=1-\Sigma\left(\mathrm{P}_{\mathrm{ij}}\right)^{2}
$$

where $P_{i j}$ is the frequency of the $i^{\text {th }}$ pattern revealed by the $\mathrm{j}^{\text {th }}$ primer combination, summed across all patterns revealed by the primers (Botstein et al. 1980). The marker index (MI), a universal metric to represent the amount of information obtained per experiment for a given kind of marker (Powell et al. 1996), was also calculated for each RAMP PC as:

$$
\mathrm{MI}=\mathrm{PIC} \times \eta \beta
$$

where PIC is the mean PIC value, $\eta$ the number of bands, and $\beta$ the proportion of polymorphisms.

\section{RESULTS}

Each primer combination was tested for its ability to generate a RAMP banding pattern. Table 1 lists the RAMP markers and gives percentages for the PCR products amplified in the three genotypes studied. The use of 21 primer combinations gave 145 scorable bands, 139 of which $(95.862 \%)$ were polymorphic, with an average of 6.619 amplicons per PC. RAMP fragment size ranged from 0.2 to $3 \mathrm{~kb}$.

The $(\mathrm{AG})_{8} \mathrm{TC} / \mathrm{OPE} 18$ primer combination gave the highest number of fragments (11 amplicons), and (AC) $)_{8}$ T/OPE04 produced the fewest (4 ampli- 
Table 1. RAMP primer combinations used in this study. TB - total bands, PB - polymorphic bands, P [\%] - polymorphic \%, PIC - polymorphic information content, MI - marker index.

\begin{tabular}{|c|c|c|c|c|c|c|}
\hline PC name & PC sequence & $\mathrm{TB}$ & PB & $\mathrm{P}(\%)$ & PIC & MI \\
\hline OPB01/ISSR1 & GTTTCGCTCC/(GACA)4 & 5 & 5 & 100 & 0.445 & 2.225 \\
\hline OPC08/ISSR 1 & TGGACCGGTG/(GACA)4 & 7 & 7 & 100 & 0.445 & 3.115 \\
\hline OPC15/ISSR1 & GACGGATCAG/(GACA)4 & 6 & 6 & 100 & 0.445 & 2.670 \\
\hline OPE04/ISSR1 & GTGACATGCC /(GACA)4 & 6 & 6 & 100 & 0.445 & 2.670 \\
\hline OPE18/ISSR1 & GGACTGCAGA/(GACA)4 & 8 & 8 & 100 & 0.445 & 3.560 \\
\hline OPQ18/ISSR1 & AGGCTGGGTG/(GACA)4 & 5 & 5 & 100 & 0.445 & 2.225 \\
\hline OPB01/ISSR2 & GTTTCGCTCC/(AC)8T & 9 & 8 & 88.89 & 0.395 & 3.160 \\
\hline OPC08/ISSR2 & TGGACCGGTG/(AC)8T & 6 & 6 & 100 & 0.445 & 2.670 \\
\hline OPE04/ISSR2 & GTGACATGCC/(AC)8T & 4 & 4 & 100 & 0.445 & 1.780 \\
\hline OPE18/ISSR2 & GGACTGCAGA/(AC)8T & 7 & 6 & 85.71 & 0.381 & 2.286 \\
\hline OPC08/ISSR3 & TGGACCGGTG/(AG)8TC & 10 & 8 & 80 & 0.356 & 2.848 \\
\hline OPC15/ISSR3 & GACGGATCAG/(AG)8TC & 8 & 7 & 87.50 & 0.389 & 2.723 \\
\hline OPE04/ISSR3 & GTGACATGCC/(AG)8TC & 10 & 10 & 100 & 0.445 & 4.450 \\
\hline OPE18/ISSR3 & GGACTGCAGA/(AG)8TC & 11 & 10 & 90.91 & 0.404 & 4.040 \\
\hline OPQ18/ISSR3 & AGGCTGGGTG/(AG)8TC & 5 & 5 & 100 & 0.445 & 2.225 \\
\hline OPB01/ISSR4 & GTTTCGCTCC/(AG)8GTG & 5 & 5 & 100 & 0.445 & 2.225 \\
\hline OPC08/ISSR4 & TGGACCGGTG/(AG)8GTG & 7 & 7 & 100 & 0.445 & 3.115 \\
\hline OPC15/ISSR4 & GACGGATCAG/(AG)8GTG & 7 & 7 & 100 & 0.445 & 3.115 \\
\hline OPE04/ISSR4 & GTGACATGCC/(AG)8GTG & 6 & 6 & 100 & 0.445 & 2.670 \\
\hline OPE18/ISSR4 & GGACTGCAGA/(AG)8GTG & 8 & 8 & 100 & 0.445 & 3.560 \\
\hline OPQ18/ISSR4 & AGGCTGGGTG/(AG)8GTG & 5 & 5 & 100 & 0.445 & 2.225 \\
\hline Total & & 145 & 139 & - & - & - \\
\hline Mean & & 6.905 & 6.619 & 96.81 & 0.431 & 2.836 \\
\hline
\end{tabular}

cons) (Table 1). Figure 1 shows the RAMP profiles obtained using $(\mathrm{AG})_{8} \mathrm{TC} / \mathrm{OPC} 08,(\mathrm{AG})_{8} \mathrm{TC} /$ OPE04, $(\mathrm{AG})_{8} \mathrm{TC} / \mathrm{OPE} 18$ and $(\mathrm{AG})_{8} \mathrm{TC} / \mathrm{OPQ} 18$ for the three tested genotypes.

\section{DisCUSSION}

PCR amplification with 21 RAMP primer combinations gave a total of 145 unambiguous DNA fragments, with $96.81 \%$ polymorphism. In earlier work on the same species (Saleh 2011a), using 20 RAPD markers I obtained 185 scorable bands, $160(84.963 \%)$ of them polymorphic; in the same study, the use of 7 ISSR markers gave 88 scorable bands, $80(90.90 \%)$ of them polymorphic.

In selected peanut genotypes, Mondal et al. (2008) obtained 119 amplicons (56 polymorphic) using 17 RAPD primers, and 153 amplicons (114 polymorphic) using 21 ISSR primers. In that study, polymorphism was higher in the products from
ISSR primers $(74.5 \%$, mean 5.4 polymorphic bands per assay) than from RAPD primers (47.1\%, mean 3.3 polymorphic bands per assay). In cotton, Noormohammadi et al. (2013) obtained 261 reproducible bands with $22 \%$ polymorphism using 26 RAPD primers, 206 reproducible bands with $49.4 \%$ polymorphism using 10 ISSR primers, and 12 alleles with $54 \%$ polymorphism using 4 SSR primer combinations.

In Limonium sinense Kuntze, Ding et al. (2013) reported polymorphism percentages lower than I found (given above: 95.862\%): $69.88 \%$ from RAPD, $71.19 \%$ from ISSR, and 70.97\% from AFLP markers. Similarly, Manners et al. (2013) reported $58.88 \%$ polymorphism in 226 amplicons obtained by RAPD and ISSR in 32 Vanda coerulea Griff ex Lindl (Blue Vanda) genotypes. Noormohammadi et al. (2013) reported higher genetic variation among cotton genotypes in the products obtained using 10 ISSR primers than in 


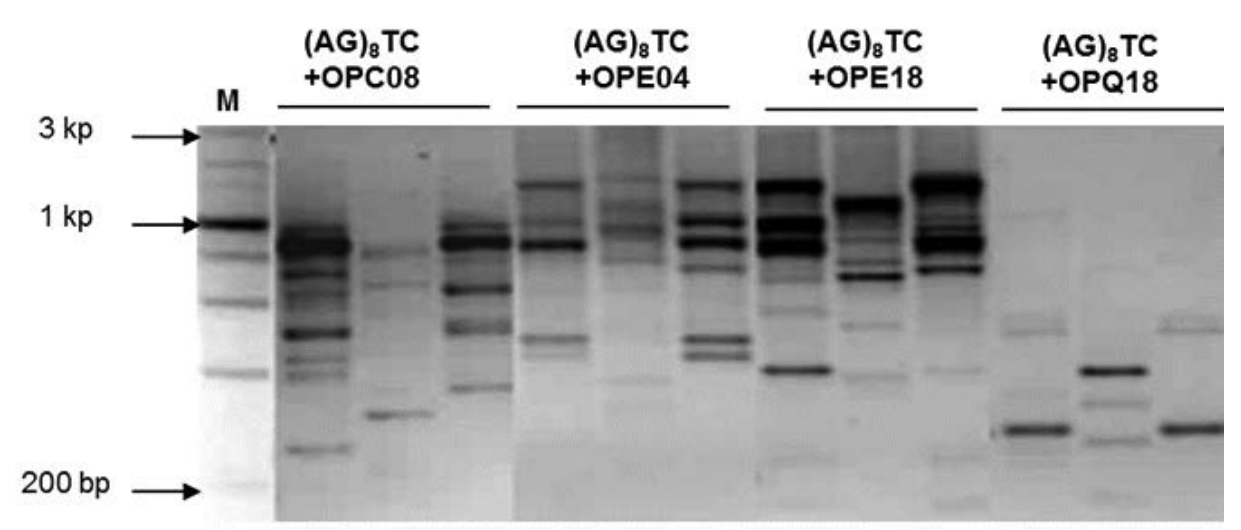

Fig. 1. RAMP banding profiles generated by $(\mathrm{AG})_{8} \mathrm{TC} / \mathrm{OPC} 08,(\mathrm{AG})_{8} \mathrm{TC} / \mathrm{OPE} 04,(\mathrm{AG})_{8} \mathrm{TC} / \mathrm{OPE} 18$ and (AG) $)_{8} \mathrm{TC} / \mathrm{OPQ} 18 \mathrm{RAMP}$ primer combinations for detection of polymorphisms in three studied genotypes of Arthrocnemum macrostachyum (Moric.) Moris. \& Delponte. $\mathrm{M}$ - DNA molecular mass marker.

those obtained using 26 RAPD primers and 4 SSR primer combinations.

In an early study, Cheng et al. (2001) used RAMP markers to investigate genetic relationships among 26 cultivars of common peach (Prunus persica (L.) Batsch var. vulgaris), 12 cultivars of nectarine (P. persica var. nectarina Maxim.), and three cultivars of flat peach ( $P$. persica var. platycarpa Bailey). Yang et al. (2006) used RAMP markers to analyze genetic diversity and similarity among 40 accessions of Leymus Hochst. (19 species, 1 subspecies). In that study, 24 (20\%) of the 120 RAMP primer combinations tested produced clear bands that were polymorphic. Of the 192 bands amplified by those 24 primer combinations, $179(93.23 \%)$ were found to be polymorphic (3-13 polymorphic bands per PC, mean 7.64 bands). Liu et al. (2009) employed RAMP to screen and characterize molecular markers linked to the tobacco black shank resistant gene.

Using 18 RAMP primer combinations and 6 AFLP primer combinations, Soumaya et al. (2011) investigated genetic diversity in 40 Tunisian datepalm cultivars. In their work, AFLP markers showed more polymorphism $(\mathrm{P} \%=97.24, \mathrm{PIC}=0.7)$ than RAMP markers $(\mathrm{P} \%=88.57, \mathrm{PIC}=0.58)$. Smolik (2012) applied various combinations of RAPD and ISSR primers in one multiplex PCR for rye gene tagging, generating a new type of R-ISSR product. Noormohammadi et al. (2012) found that combining RAPD and ISSR markers differentiated the tetraploid cotton (Gossypium hirsutum) hybrid genotype from its parents with higher resolution; they stated that combined RAPD and ISSR markers can produce new informative alleles of use for assessing genetic variation in these cultivars.

Along the same lines, in an earlier study I applied various combinations of RAPD and ISSR primers in a multiplex PCR reaction to get more genetic information and study new loci in A. macrostachyum (Saleh 2011b). The latter study revealed that R-ISSR, superior to RAPD and ISSR applied separately, is the marker of choice for investigation of genetic variability in $A$. macrostachyum. The reason for this is that RAPD or ISSR employed separately may not amplify various regions of DNA. Their binding sites (RAPD/ISSR) become more accessible for PCR amplification when these two types of markers are combined in the same PCR reaction (Bornet et al. 2002; Saleh 2011b). RAMP markers behave like SSRs, except that the polymorphism detected may not be in an SSR region. There is a tradeoff involved in using RAMP markers, however: the RAPD method is simple and broadly useful; the choice of RAMP technique reduces those two advantages.

The utility of a molecular marker depends on the PIC value and the amount of polymorphism detected among a set of accessions, expressed as $\mathrm{P} \%$. In previous work on the same species 
(Saleh 2011a) I reported PIC values of 0.377 for RAPD and 0.395 for ISSR markers, and detected polymorphism of $\mathrm{P} \%=84.963$ for RAPD markers and $\mathrm{P} \%=90.91$ for ISSR markers; by both measures, RAPD assays are of lower utility than ISSR assays. Similar findings have been reported for other species such as cultivated peanut genotypes (Mondal et al. 2008), cotton (Noormohammadi et al. 2013) and Limonium sinense (Ding et al. 2013). By the same two measures, the RAMP system applied in the present study is even more efficient $(\mathrm{P} \%=96.810, \mathrm{PIC}=0.431)$.

In analyses based on the RAMP assays, genetic distance ranged from 0.37 to 0.79 , with a mean of 0.43 (Table 2). Figure 2 is a dendrogram of the relationships between the three genotypes, constructed on the basis of UPGMA clustering. In the pattern generated from the RAMP data, the three genotypes of $A$. macrostachyum are grouped in two clusters. The first contains genotypes 1 and 3 , closely related at $\mathrm{PDV}=0.37$ (Jaccard index 0.47 ) (Table 2), and the second contains genotype 2, which is genetically distinct from the two others. The present results from RAMP assays are in accord with those from the previous work using RAPD and ISSR markers (Saleh 2011a), in which genotype 2 is genetically distinct from genotypes 1 and 3, suggesting that $A$. macrostachyum genotype 2 should be at the rank of subspecies.

The observed differences between the three genotypes at genomic level are correlated with phenotype: the presence of flowers in genotype 2, and their absence in genotypes 1 and 3. In my work with these three accessions, genotypes 1 and 3 have never produced visible flowers. This character is a primary criterion of plant taxonomy. A spiciform inflorescence of highly reduced flowers is consid-

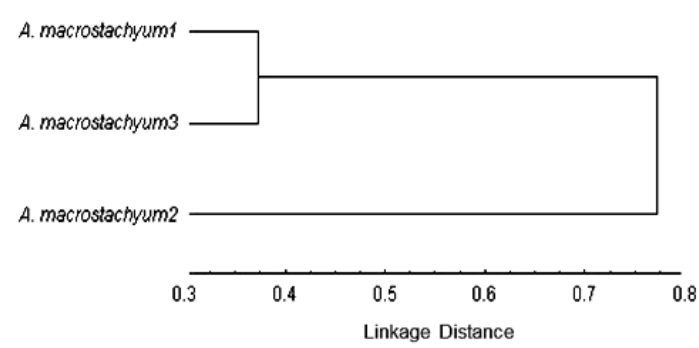

Fig. 2. UPGMA cluster analysis based on PDV values, showing genetic relationships among the three studied genotypes of Arthrocnemum macrostachyum (Moric.) Moris. \& Delponte.

ered diagnostic for Salicornioideae (Dalby 1962; Wilson 1980; Kühn et al. 1993).

In a comparison of my RAPD and ISSR PCRbased work (Saleh 2011a) and the current RAMPbased study, the Mantel test showed a highly positive correlation between the RAPD and ISSR markers $(r=0.997)$, with better fit than that estimated between ISSR and RAMP $(r=0.756)$ and between RAPD and RAMP $(\mathrm{r}=0.704)$.

Arthrocnemum macrostachyum is an important source for genes involved in salinity tolerance. It needs to be studied exhaustively so that its potential use for improvement of salt tolerance in crop plants can be fully realized, allowing marginal land to be exploited. Molecular markers offer a tool for mapping genes involved in salt tolerance. In this study I used RAMP PCR markers to analyze genetic variation in $A$. macrostachyum. This system proved to be a successful method for genetic fingerprinting of this species, better than the molecular markers employed in my previous work on the same species. It separated A. macrostachyum species into two genetically distinct subspecies. In Syria the exact number of A. macrostachyum infrataxa is not known. Further

Table 2. Percent disagreement values and Jaccard's similarity coefficients for the 21 RAMP primer combinations, from UPGMA analysis.

\begin{tabular}{lccc|lcrl}
\hline \multicolumn{3}{c|}{ Percent disagreement values } & \multicolumn{4}{c}{ Jaccard's similarity } \\
\hline Genotype & 1 & 2 & 3 & Genotype & 1 & 2 & 3 \\
\hline A. macrostachyum1 & 0.00 & & & A. macrostachyum 1 & 1.000 & \\
A. macrostachyum 2 & 0.79 & 0.00 & & A. macrostachyum & 0.087 & 1.000 \\
A. macrostachyum3 & 0.37 & 0.75 & 0 & A. macrostachyum3 & 0.465 & 0.121 & 1.000 \\
\hline
\end{tabular}


screening is needed, and chloroplast DNA may hold important information about genetic relationships within this species.

ACKNOwLEDGEMENTS. I thank Professor Othman Ibrahim (Director General of AECS) and Professor MirAli Nizar (Head of Molecular Biology and Biotechnology Department) for their support, the Plant Biotechnology Group for technical assistance, and the anonymous reviewers for helpful remarks on the manuscript.

\section{REFERENCES}

Barkoudah Y., Darwish A. I. \& Abi Antoun M. 2000. Biological diversity. National Report. Biodiversity Strategy and Action Plan and Report to the Conference of the Parties NBSAP Project SY/97/G31. http://www.informea.org/ sites/default/files/reports/national/sy-nr-01-en.

Bornet B., Goraguer F., Joly G. \& Branchard M. 2002. Genetic diversity in European and Argentinian cultivated potatoes (Solanum tuberosum subsp. tuberosum) detected by intersimple sequence repeats (ISSRs). Genome 45: 481-484.

Botstein D., White R. L., Skolinck M. \& Davis R. W. 1980. Construction of a genetic linkage map in man using restriction fragment length polymorphisms. American Journal of Human Genetics 32: 314-331.

Cheng H. Y., Yang W. C. \& Hsiao J. Y. 2001. Genetic diversity and relationship among peach cultivars based on Random Amplified Microsatellite Polymorphism (RAMP). Bot. Bull. Acad. Sin. 42: 201-206.

DalBy D. H. 1962. Chromosome number, morphology and breeding behaviour in the British Salicorniae. Watsonia 5: $150-162$.

Ding G., Zhang D., Yu Y., Zhao L. \& Zhang B. 2013. Analysis of genetic variability and population structure of the endemic medicinal Limonium sinense using molecular markers. Gene 520: 189-193.

Doyle J. J. \& Doyle J. L. 1987. A rapid DNA isolation procedure for small quantities of fresh leaf tissue. Phytochemical Bulletin 19: 11-15.

Kühn U., Bittrich V., Carolin R., Reitag H., Hedge I. C., Uotila P. \& Wilson P. 1993. Chenopodiaceae. In: K. Kubitzki, J. G. Rohwer \& V. Bittrich (ed.), The families and genera of vascular plants. Flowering plants. 2: 253-281. Springer-Verlag, Berlin, Heidelberg $\mathrm{GmbH}$.

Kung H. W., Chu G. L., Tsien C. P., Cheng-Gun Ma C. G. \& Li A. J. 1979. Chenopodiaceae. In: Editorial CoMmitTEE of FRPS (eds), Flora Reipublicae Popularis Sinicae 25(2): 1-194. Science Press, Beijing (in Chinese).
LiU X. Z., YANG Y. M., He C. S., Li H. L. \& Zhang H. Y. 2009. A RAMP marker linked to the tobacco black shank resistant gene. African Journal of Biotechnology 8: 2060-2063.

MANNERS V., Kumaria S. \& TANDON P. 2013. SPAR methods revealed high genetic diversity within populations and high gene flow of Vanda coerulea Griff. ex Lindl. (Blue Vanda), an endangered orchid species. Gene 519: 91-97.

Mondal S., Sutar S. R. \& Badigannavar A. M. 2008. Comparison of RAPD and ISSR marker profiles of cultivated peanut genotypes susceptible or resistant to foliar diseases. Journal of Food, Agriculture and Environment 6: 181-187.

Noormohammadi Z., Farahani Y. H.-A., Sheidai M., GhaseMAZAden-BaraKi S. \& Alishah O. 2012. Development of RAMPO marker for assessment of genetic diversity in tetraploid cotton genotypes. Gene Conserve 11: 1-11.

Noormohammadi Z., Hasheminejad-Ahangarani F. Y., Sheidai M., Ghasemazaden-Baraki S. \& Alishah O. 2013. Genetic diversity analysis in Opal cotton hybrids based on SSR, ISSR, and RAPD markers. Genetics and Molecular Research 12: 256-269.

Powell W., Morgante M., Andre C., Hanafey M., Vogel J., Tingey S. \& Rafalski A. 1996. The comparison of RFLP, RAPD, AFLP and SSR (microsatellite) markers for germplasm analysis. Molecular Breeding 2: 225-238.

SALEH B. 2011a. Efficiency of RAPD and ISSR markers in assessing genetic variation in Arthrocnemum macrostachyum (Chenopodiaceae). Brazilian Archives of Biology and Technology 54: 859-866.

SALEH B. 2011b. R-ISSR marker as a useful tool for detection of new genomic loci in Arthrocnemum macrostachyum. Biol. Pl. 55: 327-330.

ShePherd K. A. \& Yan G. 2003. Chromosome number and size variation in the Australian salicornioidead (Chenopodiaceae) - evidence of polyploidisation. Austral. J. Bot. 51: $441-452$.

SMOLIK M. 2012. R-ISSR - Tool for generation of a new type of products, applied for the identification of putative molecular marker linked to QTL determined tolerance to nutrient deprivation stress in rye (Secale cereale L.). Notul. Bot. Horti Agrobot. Cluj-Napoca 40: 238-246.

Soumaya R. C., Baraket G., Dakhlaoui-Dkhil S., ZehdiAzouzi S. \& Trifi M. 2011. Molecular research on the genetic diversity of Tunisian date palm (Phoenix dactylifera L.) using the random amplified microsatellite polymorphism (RAMPO) and amplified fragment length polymorphism (AFLP) methods. African Journal of Biotechnology 10: 10352-10365.

Vicente M. J., Conesa E., Varez-Rogel J. Á., Franco J. A. \& MARTínEZ-SÍNCHEZ J. J. 2007. Effects of various salts on the germination of three perennial salt marsh species. Aquatic Bot. 87: 167-170.

Williams J. G. K., Kubelik A. R., Livak K. J., Rafalski J. A. \& TingeY S. V. 1990. DNA polymorphisms amplified by 
arbitrary primers are useful as genetic markers. Nucleic Acids Research 18: 6531-6535.

WILSON P. G. 1980. A revision of the Australian species of Salicornieae (Chenopodiaceae). Nuytsia 3: 3-154.

YANG R. W., Zhou Y. H., Zhang Y., Zheng Y. L. \& Dind C. B. 2006. The genetic diversity among Leymus species based on Random Amplified Microsatellite Polymor- phism (RAMP). Genetic Resources and Crop Evolution 53: 139-144.

ZoHary M. 1966. Flora Palaestina. 1. Israel Academy of Sciences and Humanities, Jerusalem.

Zohary M. 1973. Geobotanical foundations of Middle East. Gustav Fischer Verlag, Stuttgart.

Received 26 October 2014 